\title{
USO DE ÁREAS DE PROTEÇÃO AMBIENTAL: O CASO DO MANGUEZAL DA APA DE GUAPIMIRIM
}

\author{
ANDRÉ LUIZ MAGALHÃES BOTELHO' \\ LUIZ RENATO VALLEJO² \\ Universidade Federal Fluminense
}

\section{Introdução}

Com $8,13 \%$ do território nacional composto por Unidades de Conservação (UC), existem no Brasil 241 unidades de uso direto e indireto (Ministério do Meio Ambiente, 2004). Deste universo, 31 são Áreas de Proteção Ambiental (APAs), que podem incluir em sua extensão, uma ou mais unidades de conservação, de uso indireto e são administradas pelo IBAMA.

As Áreas de Proteção Ambiental (APA) segundo definição do IBAMA são:

...áreas submetidas ao planejamento e à gestão ambiental e destinam-se à compatibilização de atividades humanas com a preservação da vida silvestre, a proteção dos recursos naturais e a melhoria da qualidade de vida da população local. “

Apesar desta definição, por vezes as Áreas de Proteção Ambiental, como nos casos das APAs de Tamoio em Angra dos Reis e de Guapimirim no entorno da Baia de Guanabara, sofrem impactos decorrentes de excesso de atividades antrópicas, correndo o risco de destruição de seus ecossistemas e desequilíbrio dos biomas que deles dependem.

\footnotetext{
${ }^{1}$ Biólogo, Especialista em Organização Espacial do RJ e Mestre em Ciência Ambiental.

${ }^{2}$ Biólogo e Mestre em Geografia, Professor Adjunto do Departamento de Geografia.
} 
Além disto, segundo Araújo (2002) em uma megacidade como São Paulo, por exemplo, estima-se que mais de um milhão de pessoas vivem em áreas que deveriam ter pouca ou nenhuma ocupação por força da legislação de proteção de mananciais. Entre as áreas ambientalmente protegidas que são comumente ocupadas de forma irregular pela população de baixa renda, as Áreas de Preservação Permanente (APP) têm lugar de relevo. Estas áreas, criadas pela Lei no 4.771 , de 15/09/65, alterada pela Lei $n^{\circ} 7.803$, de 8/08/93 do Código Florestal em seu Artigo $2^{\circ}$, podem ser definidas como:

... certas áreas públicas, ou particulares, nas quais a supressão total ou parcial da vegetação natural só é permitida, mediante prévia autorização do Poder Executivo Federal, quando necessária a execução de obras, planos, atividades ou projetos de utilidade pública ou de interesse social. Como exemplo de áreas de preservação permanente podem ser citadas: as margens dos rios; ao redor de lagoas, lagos ou reservatórios d'água; e os topos de morros, montes, montanhas e serras. Por ato do Poder Público, outras áreas também podem ser definidas como de preservação permanente.

AAPA de Guapimirim (Figura 1), localizada às margens da Baía de Guanabara, Estado do Rio de Janeiro, apresenta uma área aproximada de 14.000 ha e limita-se ao Norte com a Rodovia BR-493 e a área urbana do Município de Magé; ao sul com a Serra de Itauna e Ilha de Itaoca; a Leste com a Rodovia BR-493 e o Ramal Ferroviário Itambi - Campos; e a Oeste com a Baía de Guanabara.

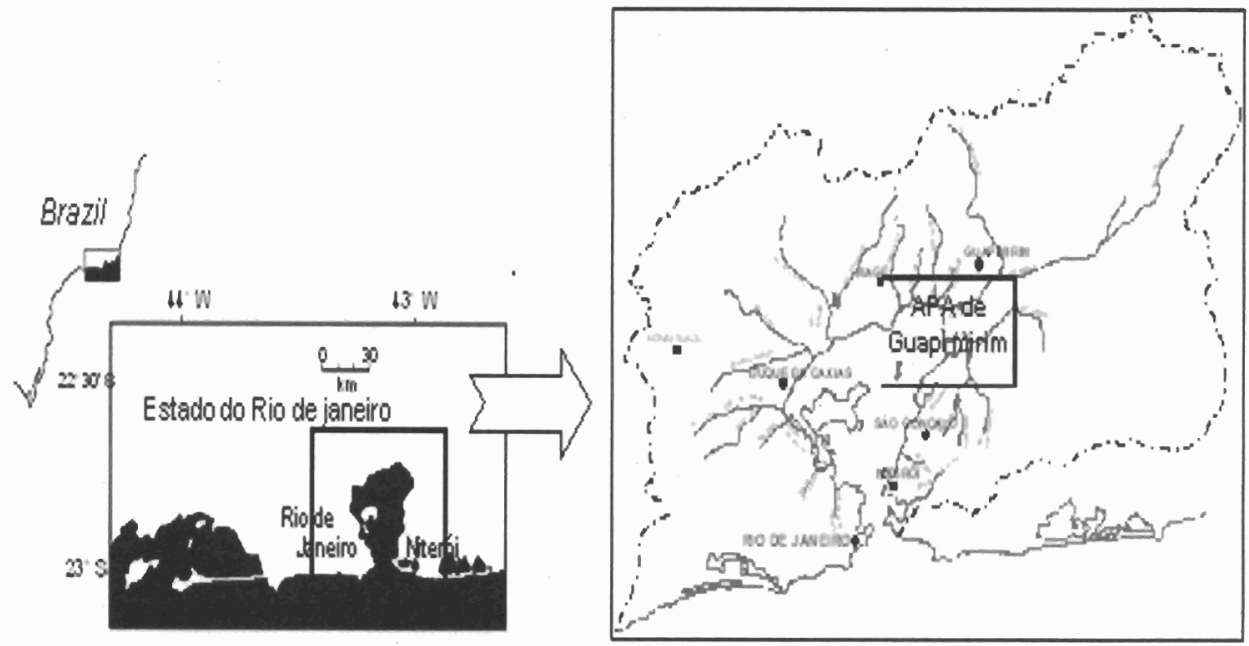

Figura 1 - Localização da APA de Guapimirim 


\section{Síntese Ambiental}

Schaeffer-Novelli et al. (1990) setorizaram o litoral brasileiro em 8 unidades (Segmentos I a VIII), conforme suas condições hidrológicas, oceanográficas, fisiográficas e climáticas, descrevendo ocorrência, distribuição e características dos bosques de mangue em cada unidade.

De acordo com esta classificação o Segmento I se localiza no trecho da região do Cabo Orange $\left(04^{\circ} 30^{\prime} \mathrm{N}\right)$ até o Cabo Norte $\left(01^{\circ} 40^{\prime} \mathrm{N}\right)$; o Segmento II no recorte entre Cabo Norte e Ponta Curuçá (00³6'S); desta a Ponta Mangues Secos (02 ${ }^{\circ} 15^{\prime}$ 'S) localiza-se o Segmento III; de Mangues Secos ao Cabo Calcanhar (050.'S) o Segmento IV; o Segmento V está inserido entre Cabo Calcanhar e o Recôncavo

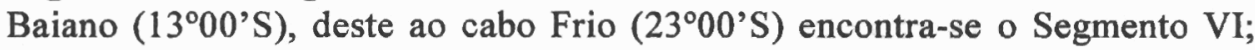

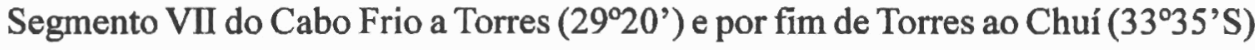
o segmento VIII.

Ainda segundo estes autores o Segmento VII é marcado pela estrutura cristalina da Serra do Mar, por planícies costeiras formadas por sistemas de lagunas e barreiras, assim como reentrâncias enseadas e baías que formam áreas abrigadas onde se desenvolvem manguezais. Ao longo deste segmento as regiões com maior ocorrência de manguezais, no Rio de Janeiro, são as Baías de Guanabara, Sepetiba e Ilha Grande.

O Manguezal de Guapimirim, último trecho representativo de manguezais da orla oriental da Baía de Guanabara, conhecida também como "Recôncavo da Baía de Guanabara", que desempenha importante papel para a qualidade de água e vida da baía vem sofrendo há décadas desmatamento constante, apresentando condições bastante críticas quanto ao seu equilíbrio ecológico e geomorfológico (PIRES et al., 1996).

A Área de Proteção Ambiental (APA) de Guapimirim foi criada em 25 de setembro de 1984, pelo Decreto Federal $n^{\circ} 90.225$, atendendo, na época, ao pleito de universidades, movimentos ambientalistas e da Sociedade Brasileira para o Progresso da Ciência - SBPC, tornando-se a primeira unidade de conservação específica de manguezais.

De acordo com a geomorfologia da costa Pacífica da América Central, (JMENEZ, 1999) classificou os manguezais em dois grupos em função de processos costeiros: ambientes com fortes ondas e barreira arenosa, onde o elemento geomorfológico principal é o cordão arenoso; e ambientes com baixa energia de ondas e grande amplitude de marés sem barreira física entre o bosque e a massa de água principal.

Nesta última classificação enquadra-se a APA de Guapimirim, onde o efeito das ondas é reduzido e as formações estruturais fisiográficas são de pequeno desenvolvimento; os bosques são em geral dominados pela espécie vegetal Rhizophora mangle e em suas partes internas há influência direta dos rios com redução na salinidade permitindo um maior desenvolvimento e diversidade de bosques. 


\section{Manguezais}

Os ecossistemas de manguezal são encontrados nas zonas tropicais e subtropicais entre $32^{\circ} 20^{\prime} \mathrm{N}$ e $38^{\circ} 45^{\prime} \mathrm{S}$ (SAENGER \& LUKER, 1997), tanto nas Américas como na África, Ásia e Oceania, dominando cerca de $25 \%$ das linhas costeiras do planeta e cerca de $75 \%$ da zona intertropical (SPALDING et al., 1997).

A despeito de sua distribuição sincopada, os manguezais se comportam como os ecossistemas mais presentes e relativamente homogêneos da costa atlântica tropical brasileira (AB'SABER, 2003).

Só nas duas últimas décadas, a imensa importância dos manguezais foi reconhecida e, dos $25.000 \mathrm{Km}^{2}$ de mangues presentes no Brasil por ocasião de sua descoberta, restam apenas cerca de 35\%. (HERZ, 1991).

O Estado do Rio de Janeiro abriga $131 \mathrm{~km}^{2}$ de mangues dos quais $80 \mathrm{~km}^{2}$ estão na Área de Proteção Ambiental de Guapimirim, que engloba os manguezais da porção oriental, nos municípios de Magé, Guapimirim, Itaborai e São Gonçalo, entre as coordenadas geográficas $22^{\circ} 40^{\prime}-22^{\circ} 46^{\prime} \mathrm{S}$ e $42^{\circ} 57^{\prime}-43^{\circ} 07^{\prime} \mathrm{W}$. Estes $80 \mathrm{Km}^{2}$ representam hoje apenas $40 \%$ dos $260 \mathrm{~km}^{2}$ outrora existentes (SEMADS, 2001).

Entre 1921 e 1931, a enseada de Manguinhos perdeu 1,8 $\mathrm{km}^{2}$ para os aterros e os manguezais dessa parte da Baía de Guanabara sofreram redução de 2 milhões de metros quadrados, além disto até a década de 20 , este estuário foi transformado em depósito de lixo (SEMADS, 2001).

As áreas de manguezal são representativas de zonas de elevada produtividade biológica, uma vez que, pela natureza de seus componentes, nelas são encontrados representantes de todos os elos da cadeia trófica marinha (CHAPMAN, 1976). Do ponto de vista ecológico, os manguezais são de grande importância no que concerne à cadeia alimentar marinha, sustentada pela formação de compostos orgânicos importantes neste ecossistema, a partir da mistura de matéria orgânica proveniente da degradação das folhas das árvores, com as partículas do sedimento e os excrementos dos animais vertebrados e invertebrados (BOTO \& BUNT, 1981).

Quando os manguezais estão em terrenos baixos ou de médio teor de salinidade, aos bosques de mangues, fixados sobre terreno lamacento, pode-se atribuir diversas funções, tais como: controlador de inundações, estabilizador de costas e controlador antierosivo, retentor de sedimentos e elementos tóxicos, retentor de nutrientes, exportador de biomassa, via de transporte, área de recreação e turismo, fonte de recursos florestais e animais, sustentáculo da diversidade biológica (Botelho \& Vallejo, 2001).

Os manguezais podem ser tratados como um recurso renovável, porém finito, quando se considera a produção natural de ostras, caranguejos, camarões, siris e mariscos, além das oportunidades recreacionais, científicas e educacionais (Odum et al., 1982). Por outro lado, o manguezal também pode ser considerado como um recurso não-renovável, quando o espaço que ele ocupa é substituído por prédios, 
Uso de Áreas de Proteção Ambiental: O Caso do Manguezal da APA de Guapimirim

atracadouros, residências, portos, marinas, aeroportos, rodovias, salinas, etc. Há ainda, entre estas categorias outras, que condenam os manguezais a se tornarem receptáculos de despejos de efluentes líquidos, disposição de resíduos sólidos ou ao extrativismo de produtos florestais (MACIEL, 1991)

\section{Ocupação desordenada das Áreas de Proteção Ambiental}

Segundo dados da UNEP (1997) aproximadamente 60 por cento da população mundial vive em uma faixa de 100 quilômetros a partir do litoral, e mais de 3 bilhões de pessoas dependem, de uma maneira ou outra, de habitats marinhos e costeiros para alimentação, locais de construção, transporte, recreação e disposição de resíduos. Cerca de um terço das regiões costeiras mundiais estão sob risco de degradação, particularmente de fontes de poluição em terra e desenvolvimento de infraestrutura.

Muitos fatores contribuem para a diminuição das florestas de mangue, incluindo o uso de sua vegetação nas indústrias de madeira e carvão, pressões do crescimento urbano e problemas crescentes com poluição (Quarto, 2002).

Em face do crescimento populacional acelerado que ocorre nas cidades brasileiras, somado ao desemprego, a população de baixa renda tende a ocupar espaços inadequados buscando áreas para fixação de moradia e extração de produtos rentáveis. Começam então a proliferar os loteamentos clandestinos, completamente desprovidos de saneamento básico e adensando áreas que originalmente deveriam estar sendo utilizadas de forma consciente. Este quadro é comum no Brasil e pode ser observado em áreas de Proteção Ambiental nas mais diversas regiões.

Este processo teve início, nas diversas regiões brasileiras sobretudo na região sudeste no contexto do chamado "milagre econômico". Na Baixada Fluminense, fatores regionais como a construção da ponte Presidente Costa e Silva (Rio-Niterói), na década de 70 e a melhoria do acesso através da rodovia BR 101 (trecho NiteróiManilha) entre 1978 e 1983, decisivamente contribuíram para o crescimento demográfico municipal. Paralelamente ao crescimento metropolitano, formou-se um eixo de ocupação que vai de Niterói a Itaboraí, passando por São Gonçalo, com densidades demográficas crescentes (Vallejo, 1999).

Analogamente à ocupação, ocorreram ações necessárias à criação da base estrutural da pavimentação da rodovia BR 101 (trecho Niterói-Manilha) inicialmente com o desmatamento de grandes áreas de manguezal, seguido de construções de pontes, aterros, cortes de falésias, desapropriações de imóveis e dragagens intensas (Araújo, 2002).

Empreendimentos de grandes proporções geralmente atraem mão de obra barata e em grande volume. Normalmente esta força de trabalho ocupa, durante a construção, alojamentos edificados pelo empreendedor para este fim, entretanto à 
conclusão da obra, os trabalhadores em busca de novas oportunidades de trabalho, se "acomodam" na própria área ou nas áreas de entorno. Exemplo deste comportamento pôde ser observado também no município de Angra dos Reis, ainda na década de 70, devido a necessidade de mão de obra para atender as demandas do Complexo Termonuclear (Botelho \& Vallejo, 2001).

Um exemplo desta situação na área de manguezal de São Gonçalo (APA de Guapimirim - Figura 2) está no distrito de Itaóca, onde no princípio dos anos 90 iniciou-se uma invasão e o processo de favelização. A população na área é constituída de pescadores, catadores de caranguejo e barqueiros; porém em face ao desemprego na cidade novos atores têm sido somados a esta população, contudo a necessidade financeira faz com que estes não respeitem a legislação de proteção das espécies e desconsiderem períodos de defeso e práticas adequadas à captura de animais aumentando o esforço de captura e utilizando-se de técnicas predatórias.

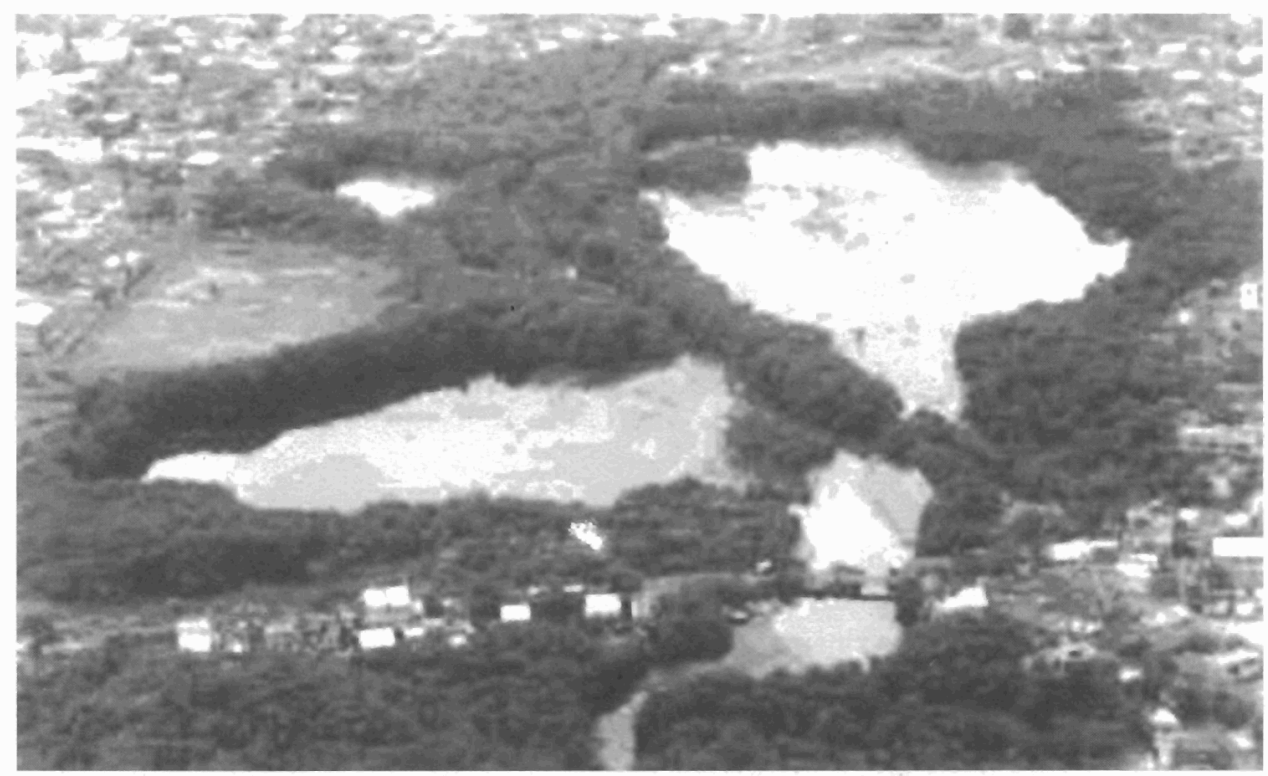

Figura 2 - Expansão da malha urbana de São Gonçalo sobre o manguezal da APA de Guapimirim. Fonte: Luciana Carneiro - www. baiadeguanabara.com.br/imagem.htm

No caso de caranguejos, diversos métodos eficientes e predatórios de captura têm sido utilizados, tais como o "saco de ráfia" (Figura 3), o uso do óleo queimado, o gás, o carbureto, o gancho, a enxada, a foice, o laço, a redinha, e a rede de braça (PEREIRA Filho, 2003); soma-se o aumento do esforço de captura sobre as fềmeas e indivíduos de tamanhos menores além da poluição dos corpos d'água e a degradação dos bosques para o desequilíbrio da população. 
Uso de Áreas de Proteção Ambiental: O Caso do Manguezal da APA de Guapimirim

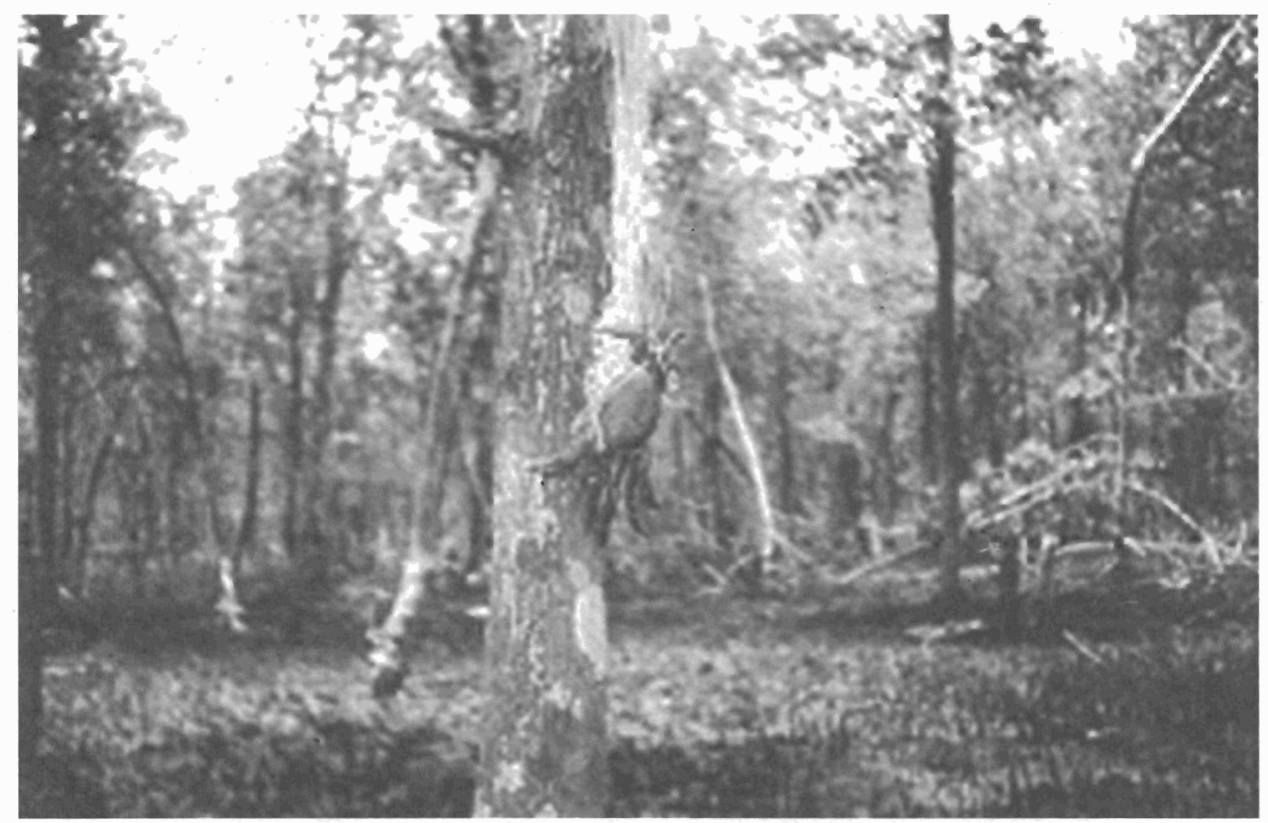

Figura 3 - Captura predatória caranguejo com uso de "sacos de rafia".

Censos realizados pelo IBGE no período de 1970 até 2000 demonstram um aumento populacional expressivo nos municípios da Baixada Fluminense integrantes da APA de Guapimirim (Figura 4), sendo que em São Gonçalo, observamos o maior contingente populacional.

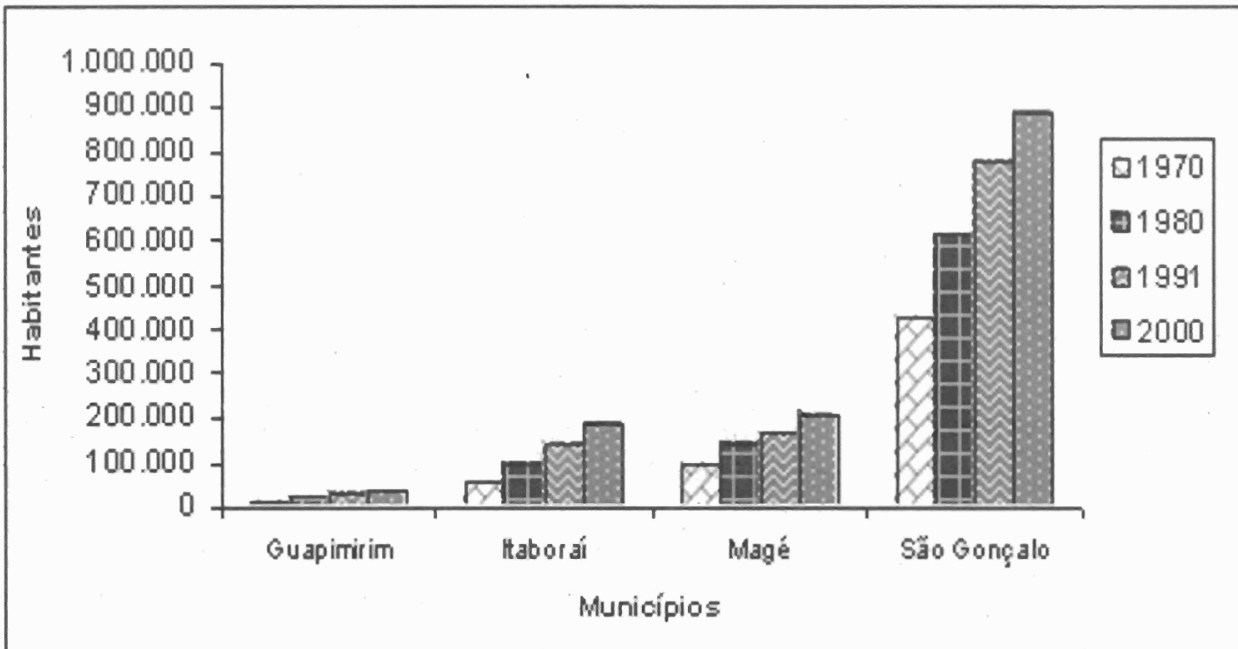

Figura 4-Aumento poputacionat dos munictpios integrantes da APA de Guapimirim Baixada Fluminense no período de 1970 a 2000. Fonte: IBGE 
A análise das taxas de crescimento populacional entre 1970 e 2000 (Figura 5), revela que o maior índice ocorreu no município de Itaboraí $(4,20 \%)$ seguido de Guapimirim (3,27\%). Já as taxas apresentadas pelos municípios de Magé e São Gonçalo, foram muito semelhantes entre si (2,49\% e $2,46 \%$, respectivamente).

Entretanto analisando por decênio fica evidente que a maior taxa de crescimento da região ocorreu na década de 70 . Também no município de Itaboraí $(5,79 \%)$ novamente seguido de Guapimirim $(4,83 \%)$. Neste período, os municípios de São Gonçalo (3,64\%) e Magé (3,82\%), apresentaram novamente as menores taxas de crescimento e similares entre si.

Na década de 90 o município que apresentou maior taxa de crescimento foi o de Guapimirim (3,43\%) acompanhado por Itaborai (3,32\%), ambos seguidos de Magé $(2,57 \%)$; São Gonçalo foi o município que deteve a menor taxa de crescimento $(1,48 \%)$ neste recorte temporal.

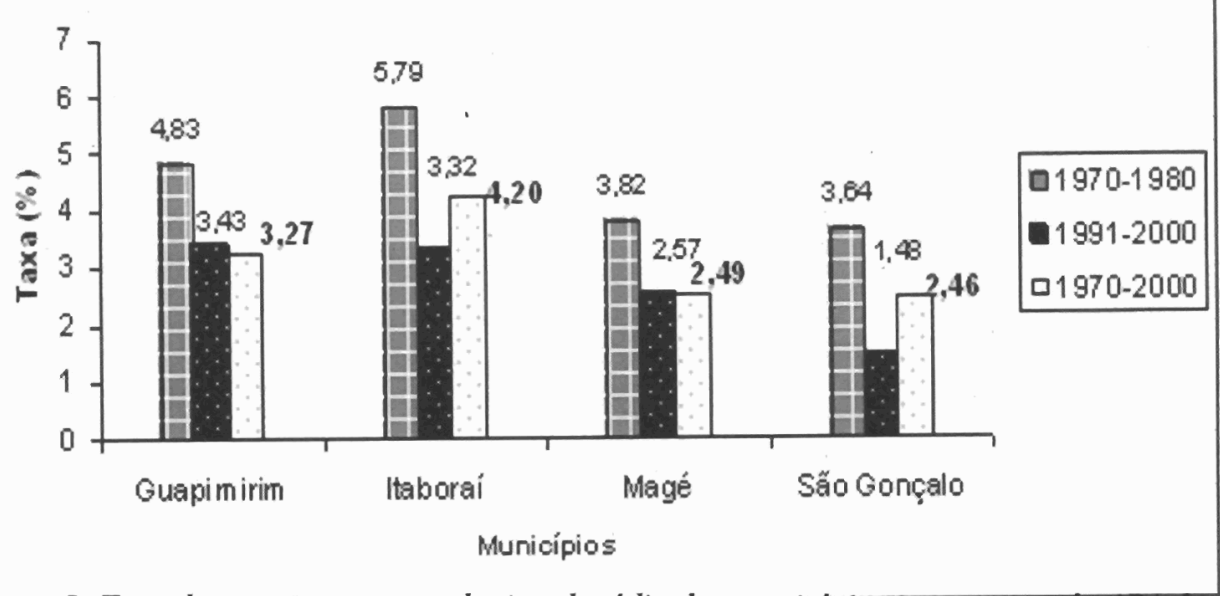

Figuras-faxa de crescimento poputactonat médto dos municiplos integrantes da APA de Guapimirim - Baixada Fluminense por decênio e no período de 1970 a 2000.

Fonte: $I B G E$

A ocupação irregular em áreas de ecossistemas tão sensíveis, como no caso dos manguezais, acarreta diversos problemas ao equilíbrio ambiental e conseqüentemente às atividades sócio-econômicas que dele dependem. Além disso a presença humana, em geral, ocasiona degradação espacial, seja por alterações físicas da área através de edificações, seja pela geração de resíduos sólidos e efluentes domésticos após a ocupação. 


\section{Uso do Solo}

Globalmente florestas de mangue representam $3 / 4$ das linhas costeiras de países tropicais e subtropicais; sendo que, atualmente mais de $1 / 4$ deste total estão degradadas (QUARTO, 2002).

Segundo (DIEGUES, 2001), nos manguezais do Maranhão, além da extração de tanino, para tintura de tecelagem e cerâmica, é também cortada madeira para utilização como mastros de barcos, e para construção de trapiches. $\mathrm{O}$ autor afirma ainda que a retirada das madeiras de grande parte dos mangues é comum em toda a Bacia do Leste.

De acordo com a FAO (1983), o gênero Rhizophora é particularmente popular pelo fato de sua madeira pesada queimar uniformemente e produzir pouca fumaça. Em vários países asiáticos o carvão é produzido em fornos abobadados construídos em locais altos próximos ao mangue.

Embora estes autores citem o uso da vegetação de mangue nas indústrias de carvão e madeira, não foram encontrados estudos apontando atividades semelhantes na APA de Guapimirim.

Contudo segundo Pires (com. pess. ${ }^{3}$ ) a queima de carvão na área, hoje uma atividade inexistente, ocorreu na década de 70; e a madeira retirada atualmente, de forma residual é destinada à montagem de "currais" ${ }^{4}$, mas apenas com a função de esteio.

Estudos da evolução da cobertura arbórea em seus diferentes estágios de regeneração no Estado são comuns, porém áreas com manguezais arbóreos não são incluídas nos mapeamentos; segundo o CIDE (2001) este procedimento é adotado devido à incerteza quanto à delimitação destas áreas.

Todavia ainda conforme CIDE (2001), apesar de ocuparem uma pequena área do Estado ( 17.193 ha ou $0,39 \%$ ), os manguezais têm grande importância no somatório da área com cobertura arbórea em alguns municípios.

\section{Perfil geral do Saneamento na Baixada Fluminense}

As condições de saneamento na Baixada Fluminense são muito desiguais, sendo o município de Niterói o que apresenta as condições mais adequadas.

Nos municípios da Baixada Fluminense, os esgotos são lançados "in natura", nos rios em canais, fossas e galerias pluviais que desembocam na Baía de Guanabara, causando sérios problemas sanitários, de inundações e de aumento da carga orgânica.

${ }^{3}$ Informação cedida pelo Prof Ivan Pires em contato telefônico.

${ }^{4}$ Estrutura de bambu montada, em geral em áreas sujeitas ao fluxo de maré, para captura de peixes. 
Os estudos sócio-econômicos realizados pelo Tribunal de Contas do Estado registraram o percentual de domicílios que lançam seu esgoto em valas ou diretamente em corpos receptores em dois municípios da Baixada Fluminense. O estudo concluiu que este percentual é superior aos $10 \%$ dos domicílios, chegando a $12,7 \%$ em São Gonçalo e atingindo os 19\% em Itaboraí. (TCE, 2003a; TCE, 2003b).

Segundo estudo realizado pela Fundação Oswaldo Cruz (Aguiar, 2003) a Baía de Guanabara recebe diariamente 470 toneladas de esgoto doméstico ( $90 \%$ sem qualquer tipo de tratamento) e sete toneladas de poluentes industriais, além de dejetos provenientes dos aterros sanitários localizados em suas margens.

Existe a informação de que o município Magés, conseguiu recursos junto a Petrobrás para construir uma Estação de Tratamento de Esgoto que atenderá seus dois distritos. O processo utilizado será o Sistema Seqüencial por Batelada, no qual o esgoto será coletado das casas e levado para a Estação de Tratamento, lá ele será tratado, filtrado e, depois de limpa a água será lançada na Baía de Guanabara.

Outra questão de saneamento enfrentada pelas cidades brasileiras é o da destinação final de resíduos sólidos gerados pela população.

No município de Niterói, com exceção das populações faveladas e a da zona leste da cidade, a coleta regular atinge $80 \%$ das residências. O lixo coletado na cidade tem como destinação final o aterro do Morro do Céu que recebe 550t/dia e encontra-se em vias de saturação.

Nos outros municípios integrantes da área da APA de Guapimirim e Baixada Fluminense, a geração estimada de resíduos sólidos é da ordem de 800t/dia e as condições dos serviços de coleta e destinação final dos resíduos sólidos são precárias.

Dados apresentados pelo TCE (2003a; 2003b) apontam que em Itaboraí 60,1\% dos domicílios são beneficiados com coleta regular de lixo, e este benefício em São Gonçalo, atinge $91,2 \%$ dos domicílios. Os outros municípios da Baixada Fluminense não figuram sob estes aspectos, do estudo.

De acordo com Azevedo (2000) existem 29 usinas de beneficiamento de lixo implantadas e/ou em implantação no Estado, dentre as quais apenas 13 encontramse no momento em operação. Ainda, segundo o autor, existem usinas nos municípios de Niterói, São Gonçalo e Magé todas previstas de realizarem os processos de segregação, Incineração e compostagem dos resíduos; entretanto todas se encontram com suas obras paralisadas. As razões mais comuns para o não funcionamento das usinas, conclui Azevedo são, de modo geral as questões operacionais, aspectos econômicos e legais, além do interesse político dos governantes.

Em face desta situação a população lança seu lixo nos rios e córregos que drenam a baixada, obstruindo a rede de drenagem, aumentando os riscos de

\footnotetext{
s Informação retirada do "site" - http://www.prefeiturademage.org/
} 
inundações e agravando os problemas sanitários. Este é o caso do lixão de Itaóca (Figura 6) que fica localizado na entrada da Ilha de Itaóca". A vizinhança com o lixão determina a vida da ilha e de sua população.

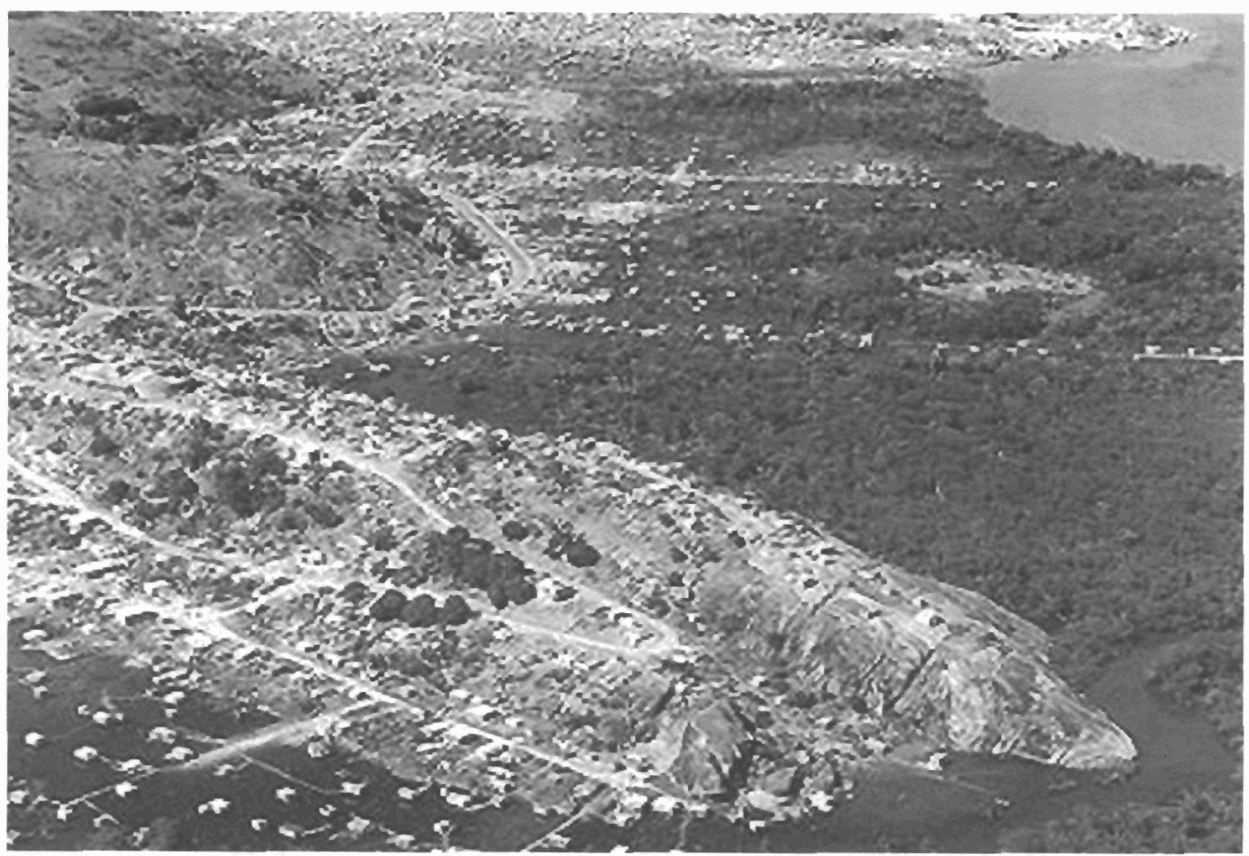

Figura 6 - Lixão de Itaóca. Fonte: www.abesrio.org.br

Este aterro vem sendo utilizado há cerca de 18 anos para disposição do lixo coletado do município de São Gonçalo e de outros.

\section{Impactos ambientais industriais}

Segundo a Secretaria Estadual de Saneamento e Recursos Hídricos (S.S.R.H., 2001), existem cerca de 6.000 industrias na bacia de drenagem da Baía de Guanabara sendo que dessas, apenas 52 são responsáveis por $80 \%$ da carga de poluentes lançada diariamente na baia.

Em relação ao grau de contaminação, os metais pesados são os elementos presentes na Baía de Guanabara em concentrações consideradas perigosas. Na Baia estes metais são em geral oriundos de descargas industriais contínuas e estão presentes na formulação do óleo cru que circula nos dutos da REDUC; entretanto acidentes com petroleiros também são comuns nas águas brasileiras e particularmente freqüentes na Baía de Guanabara, nos últimos anos. 
A presença de metais no petróleo somada ao comportamento do óleo no ambiente faz da ocorrência de vazamentos um problema multifacetado.

$O$ vazamento de óleo na costa brasileira tem sido uma ameaça permanente à integridade dos ecossistemas costeiro e marinho. Com o aumento da produção petrolífera, um grande número de ocorrências de vazamentos e derrames acidentais de petróleo em operações rotineiras (com pequena e média gravidade) tem sido registrado.

Derrames de grandes proporções em áreas costeiras causam efeitos ecológicos de curta e longa duração e trazem prejuízos às atividades sócio-econômicas nos territórios atingidos.

\section{Derramamentos agudos de petróleo}

O aporte total de petróleo para a Baia de Guanabara devido a acidentes com navios tanque levantados por Ferreira (1995) para o período de 1986 a 1993 alcança um total de $48 \mathrm{t} /$ ano.

Entretanto eventos de porte catastrófico têm ocorrido nesta virada de século, assinalando a necessidade de maiores cuidados no manejo de produtos de petróleo. $\mathrm{Na}$ baía de Guanabara, neste período, tais eventos podem ser arrolados cronológicamente a partir de março de 1997, quando um rompimento de duto provoca o vazamento de 600 mil litros de petróleo da Reduc e atinge 4.000 metros quadrados de manguezal.

Os eventos seguintes ocorreram no ano de 2000 sendo o primeiro em janeiro quando aconteceu o derramamento de 1,292 milhões de litros de óleo da Petrobrás e logo após, em junho, quando 380 litros de petróleo atingiram a baía de Guanabara. Referente ao acidente ocorrido em janeiro, laudo técnico emitido pelo Instituto Brasileiro do Meio Ambiente e dos Recursos Naturais Renováveis (IBAMA), após vistoria realizada em 22/02/2000 na APA de Guapimirim e seu entorno, o óleo causou forte impacto na área de manguezal do rio Suruí; já a área de lâmina d'água atingida pelo derrame foi avaliada em cerca de $10 \%$ da área total da APA.

O acidente ocorrido em janeiro de 2000 na Baía de Guanabara causou impactos diretos nas comunidades do entorno da Baía e indiretos à sociedade enquanto consumidora destes produtos e serviços, entretanto seus efeitos foram imediatos, pontuais e transitórios de curta duração se considerados comparativamente os efeitos e o tempo de recuperação comumente observados em eventos similares anteriores.

A imagem de satélite LANDSAT da Baía de Guanabara (Figura 7), mapeada de forma a identificar as regiões atingidas pelo óleo após vistoria para avaliação visual dos efeitos do acidente realizada no período de março de 2000 por profissionais de diversos órgãos públicos e universidades, mostra que o impacto do acidente foi mínimo se considerada a superfície da Baia de Guanabara. 


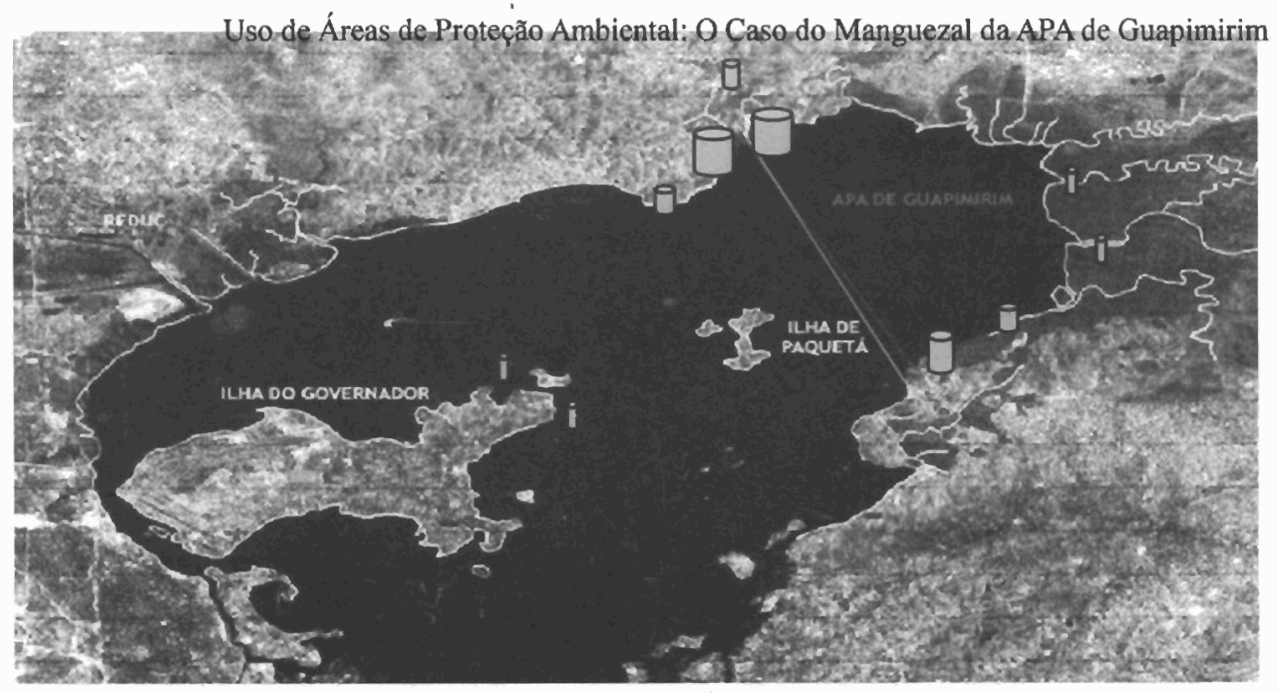

$\square$ Muito óleo Đóleo @̣ Pouco óleo O Vestigios

Figura 7 - Areas atingidas pelo derramamento de óleo em Janeiro de 2000. Fonte: Imagem satélite gentilmente cedida pelo Prof. Ivan Pires Dept ${ }^{\circ}$ Análise Geoambiental-UFF.

O manguezal da APA de Guapimirim como um todo, não se apresentava extensamente recoberto por óleo, mas apenas pequenas porções de borda do manguezal em Itaóca e em Magé (no entorno da foz do rio Suruí) se apresentavam extremamente impactados. Em relação à bacia contribuinte da APA, o rio que apresentava maior concentração de óleo em seu corpo d'água por ocasião da vistoria, era o Suruí sendo insignificante a quantidade no restante da bacia.

\section{Outras formas de impacto do petróleo}

Além da forma líquida e/ou viscosa, a presença do petróleo na Baía de Guanabara pode ser notada também na forma de produtos manufaturados, como por exemplo, pedaços de malha de redes de pesca, isopores, sacos plásticos e garrafas tipo "pet"; produtos que têm o petróleo como matéria prima e são extremamente prejudiciais à biota (Figura 8). Os organismos podem ser afetados de diversas formas, como por exemplo quando aves aquáticas e mamíferos marinhos morrem ao ingerirem ou ao se emaranharem em plásticos e redes, ou pelo tamponamento da superfície sedimentar pela deposição de plásticos ocasionando a morte da fauna e flora levando à diminuição da população de peixes da área afetada com conseqüente dano à atividade pesqueira.

Esta forma de contaminação é comum na Baía de Guanabara e freqüentemente denunciada às autoridades por pescadores atuantes na região. Na baía de Guanabara 
o lixo flutuante (Figura 9) compete com os esgotos, oriundos das áreas de maior concentração populacional, sendo levado pelas correntes superficiais e pelos ventos,

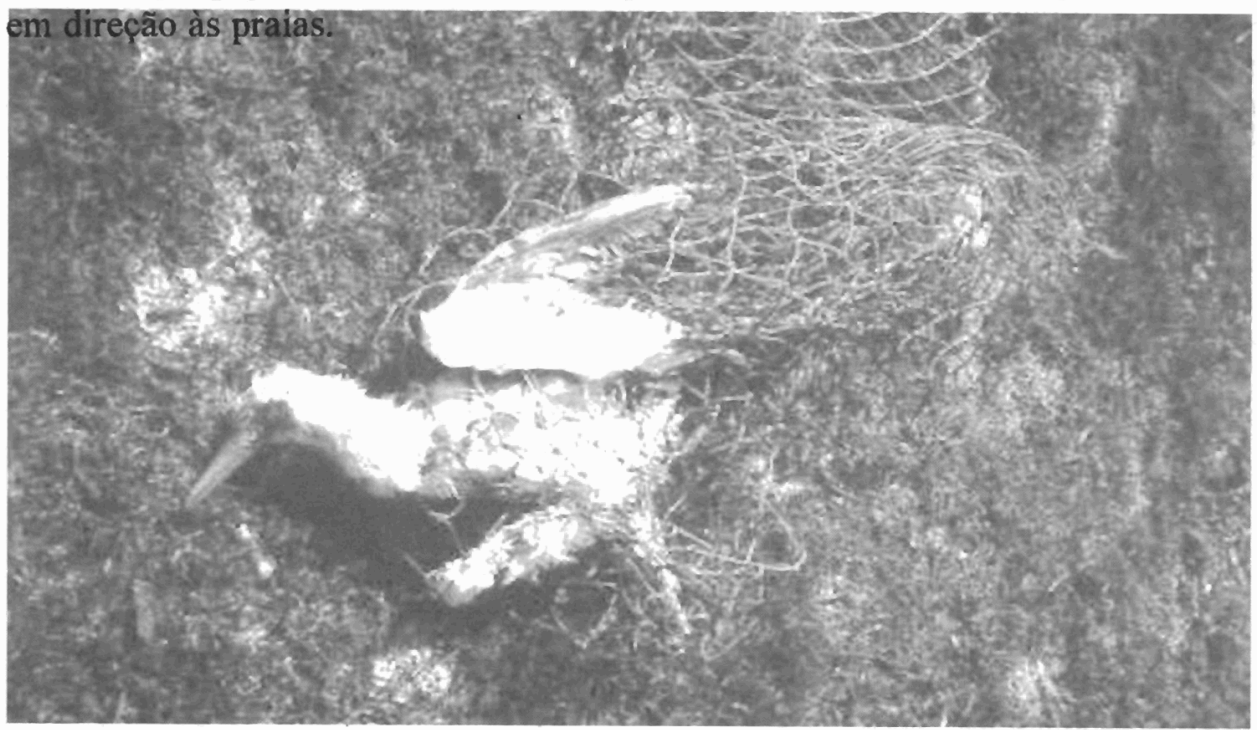

Figura 8 - Ave marinha aprisionada em redes

Esses entulhos são os causadores de assoreamentos, enchentes e inundações. Com as enchentes, além da destruição, que pode ocorrer, a população fica ainda suieita a doenças, como a leptospirose.

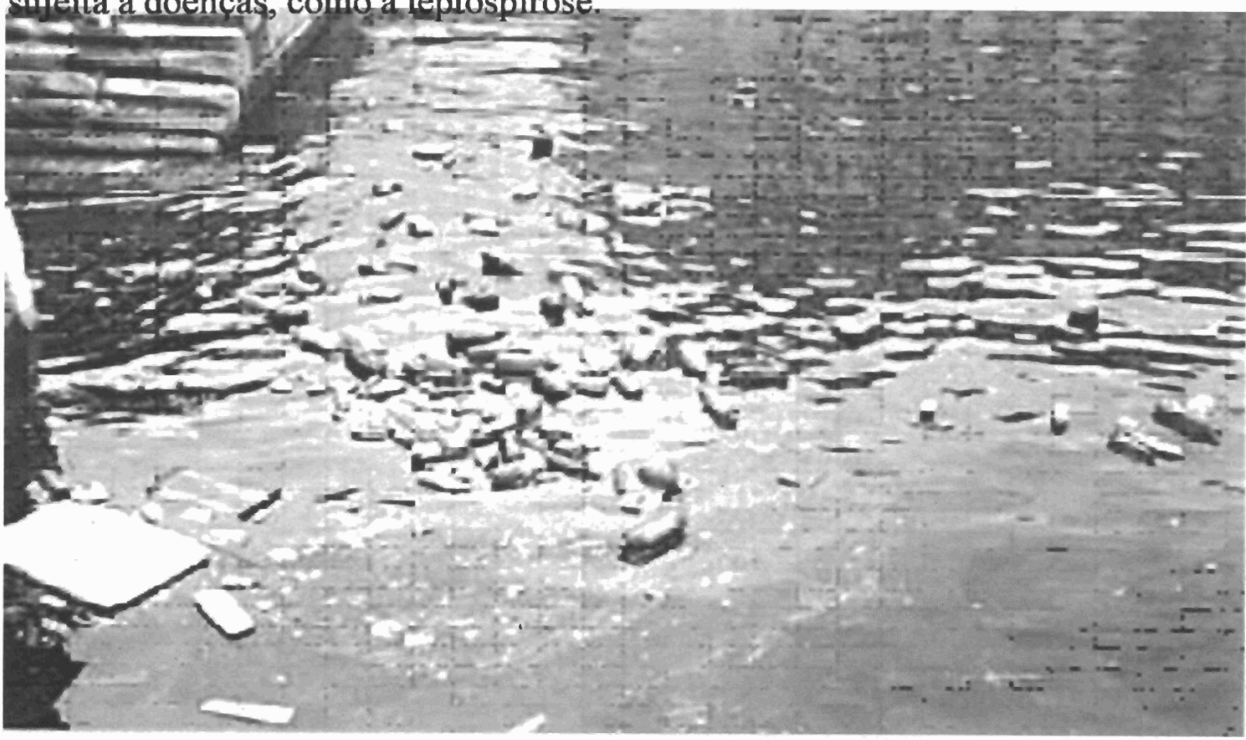

Figura 9 - Lixo Flutuante 
Uso de Áreas de Proteção Ambiental: O Caso do Manguezal da APA de Guapimirim

\section{Considerações finais}

O manguezal da APA de Guapimirim apresenta indícios de estar sendo continuamente impactado pelo uso inadequado de seus recursos e descaso em relação a sua importância por parte da população que há décadas utiliza a Baía de Guanabara como "sumidouro", entretanto apesar das diversas fontes de contaminação presentes na região, o manguezal tem se mantido intacto.

A ocupação territorial, verificada em grande escala, tem sido fator de poluição do sistema lagunar da Baía de Guanabara, por falta ainda de infraestrutura de coleta, tratamento e disposição adequada dos esgotos domésticos.

A ocupação dos municípios integrantes da APA de Guapimirim foi severa registrando os maiores indices de crescimento na década de 70 e tendendo à estabilização à partir da década de 90 . Entretanto as conseqüências desta ocupação desenfreada estão presentes ao longo de toda a APA, traduzidas em áreas de atividades agrícolas e zonas urbanas, compostas na sua maioria por pequenos núcleos - colônias de pescadores, por exemplo.

De maneira geral estes núcleos são responsáveis por alguns dos principais entraves à adequada gestão da APA, tais como aterros ilegais, invasões, vazadouros de lixo, desmatamentos, queimadas e despejo de esgoto.

Além disto a inserção de novos atores e suas necessidades na APA de Guapimirim, contribui para o desequilíbrio da dinâmica das espécies do ecossistema e descaracteriza a comunidade local.

Acidentes de grande proporções, como os ocorridos em março de 1997 e em janeiro de 2000 na Baía de Guanabara, causam impactos diretos nas comunidades do entorno da Baía e indiretos à sociedade enquanto consumidora destes produtos e serviços. Dentro da área da APA de Guapimirim, tais acidentes causam problemas ecológicos às populações biológicas residentes.

\section{USO DE ÁREAS DE PROTEÇÃO AMBIENTAL: O CASO DO MANGUEZAL DAAPA DE GUAPIMIRIM}

Resumo: Não obstante a legislação protecionista, estima-se que grande parte da população das metrópoles brasileiras viva dentro de Unidades de Conservação ou em seu entorno, sobretudo nas regiões costeiras e estuarinas. Esta proximidade expõe tais áreas ao risco ambiental devido, principalmente, à inadequada disposição de efluentes e detritos tanto domésticos quanto industriais, bem como ao seu uso e ocupação irregulares. Na APA de Guapimirim esta situação é bem caracterizada e definida por sua proximidade à cidade do Rio de Janeiro e agravada pela expansão dos municípios da Baixada Fluminense iniciada na década de 70.

Palavras-chave: Área de Proteção Ambiental (APA) - Manguezais - Guapimirim

Abstract: Despite protective legislation, it is esteemed that great part of Brazilian metropolitan population lives inside Conservation Units or in its surroundings, especially 
in coastal and estuary regions. This proximity exposes those areas to environmental risk, especially because inadequate remains and effluent disposal, from domestic or industrial sources, as well as its irregular use and occupation. In Guapimirim Law Protected Area this situation is well characterized and defined by its proximity to Rio de Janeiro city and it is aggravated with the expansion of Fluminense Lowlands municipal districts since the 70's.

Keywords: Law Protected Area - Mangroves - Guapimirim

\section{BIBLIOGRAFIA}

Ab'Sáber, A. N. (2003). Os Domínios de Natureza no Brasil: potencialidades paisagísticas. São Paulo: Ateliê Editorial.

Aguiar, R. (2003). Contaminação de peixes por compostos organoclorados na Baía de Guanabara é menor que em países industrializados. http://www.fiocruz.br/ ccs/novidades/out03/peixes_raq.htm, Fundação Oswaldo Cruz.

Araújo, S. M. V. G. (2002). As Áreas de Preservação Permanente e a Questão Urbana. Brasilia: Câmara dos Deputados. Consultoria LegislativA.

Azevedo, J. (2000). Estudo Ambiental/Econômico do Composto Orgânico do Sistema de Beneficiamento de Resíduos Sólidos Urbanos da Usina de Irajá, Município do Rio de Janeiro. Niterói. Departamento de Geoquímica. Niterói: Universidade Federal Fluminense.

Botelho, A. L. M. \& L. R. Vallejo (2001). Expansão urbana e impactos ambientais nos manguezais de Angra dos Reis - RJ. Revista de Geociências. 1: 52-67.

Boto, K. G. \& J. S. Bunt (1981). "Tidal export of particulate organic matter from a northern Australian mangrove system." Estuarine, Coastal and Shelf Science 13: 247-257.

Chapman, V. J. (1976). Coastal vegetation. New York: Pergamon Press. CIDE (2001). IQM Verde II - Índice de Qualidade dos Municípios. Rio de Janeiro: Fundação CIDE - Centro de Informações e Dados do Rio de Janeiro. Diegues, A. C. (2001). Costa do Brasil: Áreas úmidas costeiras e litorâneas. Cap. 4. Una Agenda para la Conservación de la Biodiversidad y las Políticas de Desarrollo__n:_http://www.wetlands.org/inventory\&/SAA/. E. H. Bucher, Wetlands International.

FAO (1983). Food and Agricultural Organization. Manglares: ¿Para qué sirven? Revista internacional de silvicultura e industrias forestales. 35.

Ferreira, H. O. (1995). Aporte de hidrocarbonetos de petróleo para a Baía de Guanabara - RJ. Geociências. Niterói: Universidade Federal Fluminense. Herz, R. (1991). Manguezais do Brasil. São Paulo: Instituto Oceanográfico - USP. 
Uso de Áreas de Proteção Ambiental: O Caso do Manguezal da APA de Guapimirim

Jimenéz, J.A. (1999). Ambiente, distribuicíon y características estructurales de los manglares del Pacífico de Centro America: contrastes climáticos. Ecosistemas de Manglar em America Tropical.A. Yañez-Arancibia \& A. L.LaraDominguez. Costa Rica. Mexico: Instituto de Ecologia - UICN/ORMA: 51-70.

Maciel, N. C. (1991). Alguns aspectos da ecologia do manguezal.Alternativas de uso e proteção dos manguezais do Nordeste. Recife, Companhia Pernambucana de Controle da Poluição Ambiental e de Administração de Recursos Hídricos. Congresso Pernambucano de Recursos Hidricos, Série Publicações Técnicas.

Ministério do Meio Ambiente, M. M. A. (2004). Áreas Protegidas do Brasil, http:/ /www.mma.gov.br/port/sbf/dap/apconser.html.

Odum, W. E., C. C. McIvor, et al. (1982). The Ecology of the Mangroves of South Florida: A Community Profile. Washington: U.S. Fish and Wildlife Service, Office of Biological Services.

Pereira Filho, O. (2003). Avaliação do estoque de Ucides cordatus (LINNAEUS, 1763) no manguezal utilizado pelos catadores de caranguejo de Itaoca, Baia de Guanabara, São Gonçalo, RJ. Geociências - Análise GeoAmbiental, Universidade Federal Fluminense.

Pires, I. O., C. H. Reis, et al. (1996). Relacionamento entre o terraceamento sedimentar e fisiografia característica de manguezais na região do recôncavo da Baía de Guanabara, utilizando técnicas de sensoriamento remoto e sistema de informações geográficas. VIII Simpósio Brasileiro de Sensoriamento Remoto., Salvador - Bahia.

Quarto, A. (2002). The Mangrove Forest. Mangrove Action Project, The Ramsar Convention on Wetlands.

S.S.R.H. (2001). Programa de despoluição da Baía de Guanabara. http:// www.saneamento.rj.gov.br/menu.html. Rio de Janeiro, Secretaria Estadual de Saneamento e Recursos Hídricos.

Saenger, P. \& G. Luker (1997). Some phytogeographical considerations. World Mangrove Atlas. C. Field. Okinawa: The International Society of Mangrove Ecosystems - ISME.

Schaeffer-Novelli, Y., G. Cintrón-Molero, et al. (1990). "Variability of mangrove ecosystems along the Brazilian coast." Estuaries 13(2): 204-219.

SEMADS (2001). Projeto PLANÁGUA - SEMADS / GTZ de Cooperação Técnica Brasil - Alemanha. 10 - Ambiente das águas do Estado do Rio de Janeire. Rio de Janeiro, Secretaria de Estado de Meio Ambiente e Desenvolvimento Sustentável do Rio de Janeiro, SERLA - Fundação Superintendência Estadual de Rios e Lagoas, FEMAR - Fundação de Estudos do Mar. (10): 229. 
Spalding, M., F. Blasco, et al. (1997). World Mangrove Atlas. Okinawa: International Society for Mangrove Ecosystems.

TCE (2003a). Estudo Sócio-econômico 1997-2001. Itaboraí. Rio de Janeiro: Tribunal de Contas do Rio de Janeiro - Secretaria Geral de Planejamento. TCE (2003b). Estudo Sócio-econômico 1997-2001. São Gonçalo. Rio de Janeiro: Tribunal de Contas do Rio de Janeiro - Secretaria Geral de Planejamento. UNEP (1997). Global Environmental Outlook 1 in Global States of Environmental Report, United Nations Environmental Programme.

Vallejo, L. R. (1999). "Município de Itaboraí - um estudo ambiental integrado." Cadernos do Departamento de Geografia 2(2): 21-33. 